\title{
RELATIONSHIP BETWEEN POSTURAL ALIGNMENT IN STANDING BY PHOTOGRAMMETRY AND STATIC BALANCE IN CHILDREN WITH DISABILITIES
}

\author{
Aija Klavina \\ Zinta Galeja \\ Latvian Academy of Sport Education
}

\begin{abstract}
This study was executed to explore correlation between postural alignment in standing measured through photogrammetry and static balance in children with visual, hearing, intellectual and physical disability. METHODS: Participants were 34 children (age 7-12 years) including 8 children with hearing, 8 with visual, 6 with physical, and 12 children with intellectual disabilities Postural alignment in standing was measured through photogrammetry. Static balance data were obtained in $15 \mathrm{~s}$ bipedal stance with eyes open and eyes closed, and also in $10 \mathrm{~s}$ unipedal stance. A force plate was used to collect data of Centre of Pressure amplitude in anterior-posterior, medio-lateral directions and velocity. Correlation was obtained using Spearman's Rank Correlation co-efficient in SPSS software (version 19.0). RESULTS: Moderate positive correlation ( $r=0.338$ to $r=425 ; p \leq 0.05$ ) was found between angle of head position and angle of frontal and sagittal ASIS and PSIS level. Also, moderate positive correlation was found between angles in shoulder level and angles of the head $(r=.365$ to $r=.453, p<.05)$. In assessing the static balance outcomes between the four groups, results presented significant differences in results during bipedal stance with eyes open. CONCLUSION: Degree of forward head posture correlates directly with hip and shoulder anatomical placement. Children with intellectual disability presented larger displacement of the center of pressure with more body sway observed during eyes open condition.
\end{abstract}

Keywords: children with disability, posture, static balance.

\section{Introduction}

Posture indicates the relationship between spinal segments and the environmental factors. The upright posture is considered important indicator of musculoskeletal health, particularly in children. Therefore, prevention and screening for risk factors of postural deviation in childhood is important. Moreover, the results of previous studies indicated that disability increases risk of postural deformations in children with hearing and visual impairments (Zwierzchowska \& Gawlik, 2007; Ray, Horvat, Croce, Mason, \& Wolf, 2008) and intellectual disability (Hill \& Goldsmith, 2010). There is no standard 
Aija Klavina, Zinta Galeja. Relationship Between Postural Alignment in Standing By

Photogrammetry and Static Balance in Children with Disabilities

approach to measuring posture. Photographic observation is one of the most frequently used clinical assessment of postural alignment based on non invasive techniques that is cost effective and appropriate for screening evaluations (Lafond, Descarreaux, Normand, \& Harrison, 2007; McEvoy \& Grimmer, 2005).

Development of postural control is an important prerequisite for the performance of movement maturation. Different motor tasks require a person to maintain his or her center of gravity over the base of support (Rain \& Twomey, 1994). Fundamental changes take place in postural control during child development. While young children show large and fast alterations of the center of pressure (COP), around 7 to 8 -years of age the COP shows smaller and slower deviations during standing. This postural improvement has been linked to improvement of reception of proprioceptive, visual, vestibular information and to maturation of sensorimotor integration (Kirshenbaum, Riach, \& Starkes, 2001).

Postural characteristics and the development of balance associated with the motor control theory have been explored for many decades in healthy children (Assiante, 1998; Kohen - Raz, 1970; Woollacott \& Shumway - Cook, 1990). In special population the quantitative analyses of posture has been generally exploited on children with musculoskeletal pathologies (Dewar, Love, \& Johnston, 2014; Ribot - Cisacar, Trefouret, Aimonetti, Attarian, \& Poget, 2004). However, few researchers have extended the application of quantitative posturography in children with cognitive challenges (e.g., Geuze, 2003; Poblano et al. 2002). While postural rehabilitation often plays an important role in contemporary clinical management in of postural problems in pediatric population, there is still paucity of studies investigating postural correlations in children with variety of health pathologies. Despite the documentation, assessment of posture, balance and motor deficits of children with mild and moderate disabilities (Gheysen et al., 2008; Pavao et al, 2013; Poliszczuk \& Rutkowska, 2006; Sharon et al., 2008), they are not included in therapeutically directed physical activity sessions unless obvious neurological or orthopedic disorders are diagnosed. Physical education teachers and parents of children with mild visual, hearing and/or physical disabilities often report impaired coordination and balance that may hinder the child's optimal growth and maturation in future. Moreover, more frequently researchers have examined either the motor skill performance or body composition, or posture and postural control in single disability group, while the associations among the different body systems across variety of disability groups have not been investigated in elementary school age children population. This study aimed to complement previous studies on relationship between posture alignment and postural control function that in turn can affect movement potential, health and wellbeing of children with different disabilities. Furthermore, the results of such research can help to target health promotion and physical activity intervention programs to this population. 


\section{Methods}

Participants were 34 children (15 girls, 19 boys) representing four subgroups of mild to moderate functional impairments: (1) 8 with visual impairment (VI) of whom none was blind, (2) 12 with mild intellectual disability (ID), (3) 6 with physical impairment (PI) of whom five with cerebral palsy (GMFCS Level I-II) and one with musculoskeletal deformation, and (4) 8 with hearing impairment (HI). Participants mean age was 10 years 5 months $(\mathrm{SD}=1.2)$. Two children had obesity (BMI was 20.0 and 27.0) and one had overweight (BMI was 19.8), all boys - with ID, HI and PD, respectively. Two girls with HI had underweight (BMI 14.5 and 12.9). All participants were selected from special education schools in Latvia and met following criteria: (1) age between 7-11 years old, (2) ability to follow verbal or visual (for hearing impaired) instructions; (3) ability to demonstrate locomotor and manipulative skills from the TGMD-2, however, the results of the TGMD will not be analyzed in this manuscript. The exclusion criteria included any accompanying health problems that might influence physical activities (e.g., severe intellectual disability, severe autism, seizures, diabetes, asthma, cardiopulmonary disease).

The study was approved by the Ethical Committee of the Latvian Academy of Sport Education and confirmed to the Helsinki Declaration (1964). All participants and/or their parents/guardians provided written consent priori to the study.

For postural alignment, in total, 102 pictures were taken from the anterior, and posterior directions (frontal plane) as well as from both sides (sagittal plane). A digital camera (Nikon D5000) was positioned at a standard distance of $5.00 \mathrm{~m}$ from the platform at a height of $1.20 \mathrm{~m}$. The subjects wore bathing clothes and/or shorts and top. Pictures were taken with subjects in the standing position to allow the visualization of 15 anatomic points: (1) cansus; (2) glabella; (3) mental protruberance; (4) tragus of the ear; (5) medium point, acromion; (6) sternoclavicular joints; (7) iliac crest; (8) anterior-superior iliac spine (ASIS); (9) femur, greater trochanter; (10) patella, medium point; (11) tibia tuberosity; (12) spinal process of C7 and T3; (13) scapula, inferior angle; (14) seventh thoracic vertebrae; (15) posterior-superior iliac spine (PSIS) (Kendall, 1994). The software ArchiCAD program was used to analyse data.

Postural control / static balance measurements were collected with two force plates, wireless EMG and two Vixta cameras ( $25 \mathrm{fps}$, BTS, Italy), all devices were synhronized. All children performed postural balance tests under two conditions: (1) bipedal standing with eyes open, and (2) bipedal standing with eyes closed. Each condition had 1 practice and 2 recording trials of $15 \mathrm{~s}$. Children were asked to stand as still as possible with their arms comfortably at their side. 
Aija Klavina, Zinta Galeja. Relationship Between Postural Alignment in Standing By

Photogrammetry and Static Balance in Children with Disabilities

Trials where voluntary movements were observed or children started talking were rejected and additional trials were performed.

Postural sway data were registered with two force plates (BTS P-6000, $60 \mathrm{x}$ $40 \mathrm{~cm}$, BTS, Italy). Data were sampled out at $200 \mathrm{~Hz}$ and the plates were calibrated before each test. For each test condition the mean amplitude of anteriorposterior (AP) and of medio-lateral (ML) displacement of the center of pressure (COP) was calculated using the Sway software (BTS, Italy). Ground reaction forces (GRF) collected from the force plates were processed and, the location of the COP was determined. The greatest displacements of the COP $(\mathrm{cm})$ in the mediolateral $\left(\mathrm{COP}_{\mathrm{ML}}\right)$ and anteroposterior $\left(\mathrm{COP}_{\mathrm{AP}}\right)$ directions were subsequently calculated.

Statistical calculations were performed with SPSS 19.0. First, the data was checked for normal distribution with a Kolomogorov- Smirnov Z test. Hence, further analysis was done with nonparametric statistics. For each measure, posture, postural stability and postural sway differences across the four groups (ID, HI, VI and PI) were tested with the Kruskal-Wallis test. Post hoc analysis with Bonferroni adjustment was used for multiple comparisons. To calculate correlation between postural alignment and static balance measures across the four groups the Spearman's correlation coefficients $(\rho)$. The correlations were interpreted as follows: $\mathrm{r}<0.20$, poor relationship; 0.21-0.40, fair; 0.41-0.60, moderate; 0.61-0.80, good and 0.81-1.00 values very good to excellent. Alpha was set at .05 .

\section{Results}

The mean age of participants was $10.5 \pm 1.2$ years. There was no difference in the mean age across the four subgroups $(\mathrm{p}>.05)$. The averaged weight of the group was $30.5 \pm 7.4 \mathrm{~kg}$ and height was $138.0 \pm 10.4 \mathrm{~cm}$ (Table 1). Children with HI were significantly higher than children with PI and ID $(p<.05)$, while there were not significant differences in weight results of participants (Table 1). Also, there was no significant deference in the mean height and weight data between boys and girls.

Results of postural alignment measures in sagittal plane indicated significant differences across the fours groups in vertical alignment of the body (mean range from .93 to 3.31, $\mathrm{p}<.05$ ) and ASIS/PSIS level (mean range from 10.20 to 17.55, $\mathrm{p}<.05)$. Children with PI had major deteriorations in vertical body alignment (3.31 \pm 1.68$)$ as well as largest asymmetry in ASIS/PSIS alignment (13.53 \pm 5.81$)$. In addition, majority of participants presented winged scapulae (33 children), shoulder protraction (32 children). In frontal plane significant differences were found only in vertical alignment of the body across the four subgroups where children with PI presented largest asymmetry $(1.85 \pm 1.13)$. 
Table 1 Mean age, weight and height of participants

\begin{tabular}{llll}
\hline Disability & Age (years, months) & Height $(\mathrm{cm})$ & Weight $(\mathrm{kg})$ \\
\hline $\begin{array}{l}\text { Intellectual disability } \\
(\mathrm{n}=12)\end{array}$ & $9.2( \pm 1.0)$ & $134.0( \pm 6.8)$ & $27.6( \pm 4.9)$ \\
$\begin{array}{l}\text { Physical disability } \\
(\mathrm{n}=6)\end{array}$ & $9.0( \pm .6)$ & $132.1( \pm 9.1)$ & $30.7( \pm 11.1)$ \\
$\begin{array}{l}\text { Hearing impairment } \\
(\mathrm{n}=8)\end{array}$ & $10.3( \pm .9)$ & $147.7( \pm 13.7)$ & $34.6( \pm 8.7)$ \\
$\begin{array}{l}\text { Visual impairment } \\
(\mathrm{n}=8)\end{array}$ & $11.3( \pm 4.9)$ & $138.4( \pm 4.7)$ & $30.4( \pm 4.9)$ \\
\hline Mean $(\mathrm{SD})$ & $9.3( \pm 1.2)$ & $138.0( \pm 10.4)$ & $30.5( \pm 7.4)$ \\
\hline
\end{tabular}

Moderate positive correlation $(r=0.338$ to $r=425 ; p \leq 0.05)$ was found between angle of head position and angle of frontal and sagittal ASIS and PSIS level. Also, moderate positive correlation was found between angles in shoulder level and angles of the head $(\mathrm{r}=.365$ to $\mathrm{r}=.453, \mathrm{p}<.05)$.

Postural control analysis of mean results during bipedal stance revealed only two significant differences across the four subgroups in two conditions. During eyes open children with ID presented larger displacement of $\mathrm{COP}_{\mathrm{AP}}$ than children with VI $(\mathrm{p}=.047)$. Also, children with ID had significantly higher value of $\mathrm{COP}_{\mathrm{ML}}$ sway than children with HI with EC condition $(p=.009)(p>.05)$ (Figure 1).

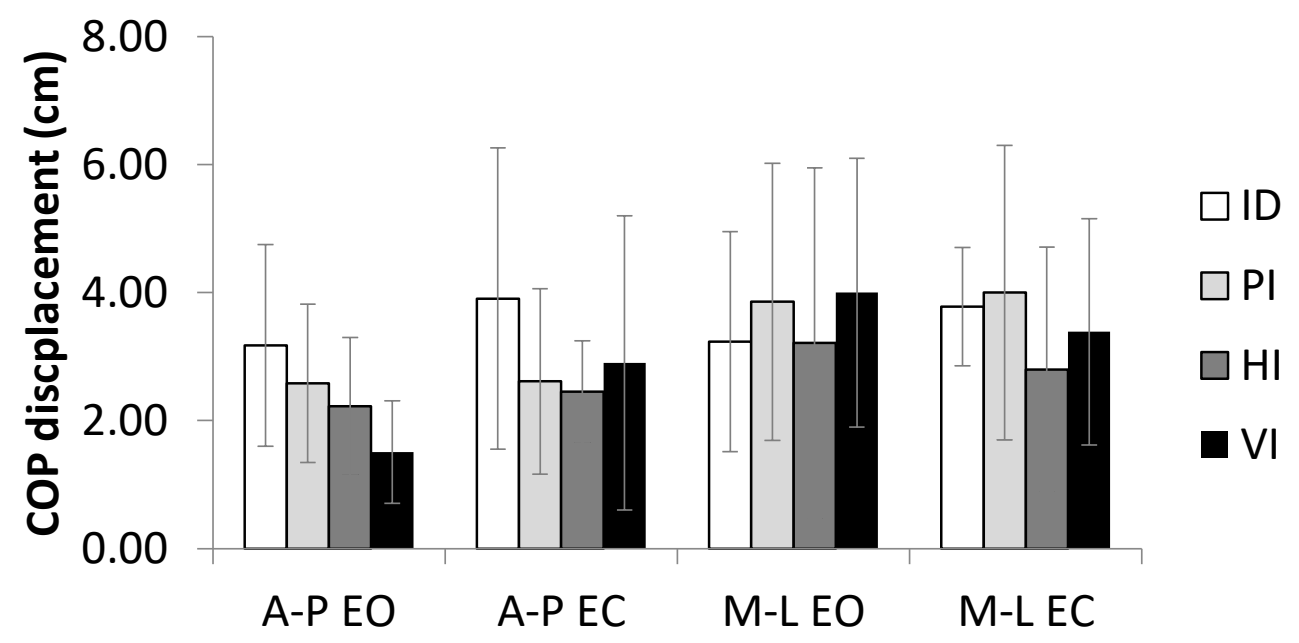

Figure $1 \mathrm{COP}_{\mathrm{AP}}$ and $\mathrm{COP}_{\mathrm{ML}}$ mean results during bipedal stance (EO- eyes open, EC - eyes closed)

\section{Discussion}

While primary school age children might have temporary postural deviations of body alignment, the musculoskeletal pathologies related to disability can adversely impact the body function in adulthood. This study explored postural 
Aija Klavina, Zinta Galeja. Relationship Between Postural Alignment in Standing By

Photogrammetry and Static Balance in Children with Disabilities

alignment deviations of children with mild to moderate visual, hearing, intellectual and physical impairments of verifying possible differences between the four subgroups with respect to the postural stability aspects. The most frequent postural deviation was winged scapulae and shoulder protraction across the four subgroups of children. Our findings were in line with other authors (Domagalska et al., 2011; Domagalska-Szopa \& Szopa, 2013). According to Kendall et al., (1993) winged scapula is common during childhood due to poor scapulothoracic fixation. In the current study, the finding of forward displacement of the vertical alignment of the body must be coupled with rearward displacement of the center of mass in order to maintain an adequate sagittal balance. On other hand, the observed postural variations can be the result of normal musculoskeletal maturation throughout childhood. The obtained results in this study might reflect an adaptation process aimed at maintaining an adequate sagittal balance and appropriate configuration in terms of musculoskeletal loads and sagittal plane curvature development (Mac-Thion et al., 2004; Cil et al., 2005). Also, several authors have suggested that postural habits and other environmental factors could influence postural development (Black, McClure, \& Polansky, 1996; Murphy, Buckle, \& Stubbs, 2004). School age children spend over $95 \%$ of their school time in a static sitting position and an average of 1.5 hours a day playing video games and using computers (Cardon, De Clercq, De Bourdeaudhuij, \& Breithecker, 2004; Marshall, Gorely, \& Biddle, 2006). According more recent data in Latvia about $23 \%$ of school age children spent more than 4 hours watching TV during working days, while $41 \%$ during weekends. Also, the time spent at the TV and computer increases with an age of children (The Center of Disease Prevention and Control of Latvia, 2013).

Thus, with the increasing time periods spent in the sitting position at home and at school, sagittal plane postural translations may increase with age throughout childhood. However, there was no strong relationship found between segmental sagittal plane analysis that was different outcome from other studies on children. The increase in sagittal ASIS/PSIS axis result in leaning forward that was found only for children with ID in our results (Cil et al., 2005). While previous studies have attempted to explore sagittal spinal and sacropelvic alignment during growth, the conclusions remain limited.

Compared to previous studies regarding postural control in children with disabilities, in general, our results did not show significant differences in displacement of the COP in the anteroposterior and/or mediolateral direction across the four groups and two conditions (EO/EC). Only two measures of children with ID were significantly different from other subgroups: between ID and VI COP $\mathrm{AP}_{\mathrm{A}} \mathrm{EO}$ and between ID -HI COP $\mathrm{ML} E \mathrm{EC}(\mathrm{p}<.05)$. The fact that no many significant differences of $\mathrm{COP}_{\mathrm{AP}, \mathrm{ML}}$ displacement measures were detected can be explained by the relatively small sample size and inherent variability in this 
population. Interestingly, all subgroups, but not ID, presented slightly larger body sway with EC condition (Figure 1). This is similar to what is observed in typically developing children. These findings extend prior observations showing that children, also those with disabilities, are more dependent visual stimuli (Shumway - Cook et al., 1985, 2001).

\section{Limitations and Future Implications}

The measures in this study were narrowly focused on relationship between posture assessment and postural control variables during quite stance. Also, the sample of children with disabilities was rather small and heterogenous, by including different types of functional limitations. Further studies should involve more participants and also include other variables that are thought to impact physical activity levels and movement proficiency. Also, further controlled longitudinal studies are necessary to understand deviations of spinal alignment and development in children with different disabilities. The non-invasive method for postural assessment should allow the selection of children in a longitudinal study to accurately define the association between age, functional limitation and postural variables. The relationship between balance and dynamic postural adjustment to task difficulty in children with functional limitations should be explored.

\section{Conclusions}

The degree of forward head posture correlates directly with hip and shoulder anatomical placement. Results indicated that distinct changes in sagittal alignment of a child's posture occur during growth, in order to accommodate for physiological and morphological changes. Children with intellectual disability presented larger displacement of the center of pressure with more body sway observed during eyes open condition. The findings of this study strengthen the perspective that the detailed assessment of body posture and balance should be included as part of routine clinical evaluation as well as educational programs in all children, including those with functional limitations.

\section{Acknowledgements}

This study was supported by the EEA/Norway Grants "Research and Scholarship" programme in Latvia and done within the project ,Health and Social Indicators of Participation in Physical Activities for Children with Disabilities" (Nr. NFI/R/2014/070). 
Aija Klavina, Zinta Galeja. Relationship Between Postural Alignment in Standing By

Photogrammetry and Static Balance in Children with Disabilities

\section{References}

Assiante, C. (1998). Development of locomotor balance control in healthy children. Neuroscience \& Biobehavioral Reviews, 22 (4), 527 - 532.

Black, K. M., McClure, P., \& Polansky, M. (1996). The influence of different sitting positions on cervical and lumbar posture. Spine, 21 (1), 65-70.

Cardon, G., De Clercq, D., De Bourdeaudhuij, I., \& Breithecker, D. (2004). Sitting habits in elementary schoolchildren: a traditional versus a "Moving school". Patient Education and Counseling, 54 (2), 133-142.

The Center of Disease Prevention and Control of Latvia (2013). Statistic data on children health in Latvia.

Cil, A., Yazici, M., Uzumcugil, A., Kandemir, U., Alanay, A., Alanay, Y., Acaroglu, R. E., \& Surat, A. (2005). The evolution of sagittal segmental alignment of the spine during childhood. Spine. 30 (1), 93-100.

Dewar, R., Love, S., \& Johnston, L. M. (2014). Exercise interventions improve postural control in children with cerebral palsy: a systematic review. Developmental Medicine \& Children Neurology, 57 (6), $504-20$.

Domagalska, M. E., Szopa, A. J., \& Lembert, D. T. (2011). A descriptive analysis of abnormal postural patterns in children with hemiplegic cerebral palsy. Medical Science Monitor, 17 (2), CR110-CR116.

Domagalska-Szopa, M. E., \& Szopa, A. J. (2013). Body posture asymmetry differences between children with mild scoliosis and children with unilateral cerebral palsy. BioMed Research International, http://dx.doi.org/10.1155/2013/462094

Geuze, R. H. (2003). Static balance and developmental coordination disorder. Human Movement Science, 22, 527 - 548.

Gheysen, F., Loots, G., \& Van Waelveld, H. (2008). Motor development of deaf children with and without cochlear implants. Journal of Deaf Studies and Deaf Education, 13 (2), 215224.

Hill, C. S., \& Goldsmith J. (2010). Biomechanics and Prevention of Body Shape Distortion. Tizard Learning Disability Review, 15 (2), 15-29

Kendall, F. P. (1994). Muscles Testing and function. New - York: W\&W. 451 p.

Kirshenbaum, N., Riach, C. L., \& Starkes, J. L. (2001). Non-linear development of postural control and strategy use in young children: a longitudinal study. Experimental Brain Research, 140, 420-431.

Kohen - Raz, R. (1970). Developmental patterns of static balance ability and their relation to cognitive school readiness. Pediatrics, 46 (2), $276-285$.

Lafond, D., Descarreaux, M., Normand, M. C., \& Harrison, D. E. (2007). Postural development in school children: a cross - sectional study. Chiropractoc \& Osteopathy, 15 (1), doi:10.1186/1746-1340-15-1

Mac-Thion, J. M., Berthonnaud. E., Dimar, J. R., Betz, R. R., \& Labelle, H. (2004). Sagittal alignment of the spine and pelvis during growth. Spine, 29 (15), 1642-1647.

Marshall, S. J., Gorely, T., \& Biddle, S. J. (2006). A descriptive epidemiology of screen-based media use in youth: a review and critique. Journal of Adolescents. 29 (3), 333-349.

McEvoy, M. P., \& Grimmer, K., (2005). Reliability of upright posture measurements in primary school children. BMC Muskuloskeletal Disorders, 6 (35) doi:10.1186/1471-2474-6-35.

Murphy, S., Buckle, P., \& Stubbs, D. (2004). Classroom posture and selfreported back and neck pain in schoolchildren. Applied Ergonomics, 35 (2), 113-120. 
Pavao, S. L., Neves dos Santos, A., Woollacott, M. H., \& Ferreira Rocha, N. A. C. (2013). ssessment of postural control in children with cerebral palsy: a review. Research in developmental disabilities, 34, 1367-1375.

Poblano, A., Ishiwara, K., de Lourdes Arias, M., Garcia - Pedroza, F., Marin, H., \& Trujillo, M. (2002). Motor control alterations in posturography in learning- disabled children. Archives of Medical Research, 33 (5), 485 - 488.

Poliszczuk, T., \& Rutkowska, I. (2006). Comparative analysis of balance skills of blind girls and rhythmic gymnasts. In: Nowocień J. (ed.) Społeczno - edukacyjne oblicza olimpizmu AWF Warszawa, 157-163

Rain, S., \& Twomey, L. (1994). Posture of the head, shoulder and thoracic spine in comfortable erect standing. Australian Journal of Physical Therapy, 40 (1): 25-32.

Ray, C. T., Horvat, M. B., Croce, R. C., Mason, C. B., \& Wolf, S. L. (2008). The impact of vision loss on postural stability and balance strategies in individuals with profound vision loss. Gait \& Posture. 28, 58-61

Ribot - Cisacar, Trefouret, Aimonetti, Attarian, Poget, J., \& Roll, J. P. (2004). Is muscle spindle proprioceptive function spared in mscular dystrophies? A muscle tendon vibration study. Muscle Nerve, 29 (6), $861-866$.

Sharon, L., Cushing, B. C., Rutka, J. A., James, A. L., \& Gordon, K. A. (2008). Evidence of vestibular and balance dysfunction in children with profound sensorineural hearing loss using cochlear implants. Laryngoscope, 118, 1814-1823.

Shumway-Cook, A., \& Woollacott, M. H. (2001). Motor control: theory and practical applications. Maryland USA: Lippincott Williams and Wilkins.

Shumway-Cook, A., \& Woollacott, M. H. (1985). The growth of stability: postural control from a developmental perspective. Journal of Motor Behavior, 17 (131-147).

Zwierzchowska, A., \& Gawlik, K. (2007). Deaf children and adolescents and defective posture. New Medicine. 2 (37-9).

Woollacott, M. H., \& Shumway-Cook, A. (1990). Changes in posture control across the life span - a system approach. Physical Therapy, 70 (12), 799-807. 